\title{
Serve and Return in Badminton: Gender Differences of Elite Badminton Players
}

\author{
Jan Carboch ${ }^{a,}$, , Petr Smocek a
}

Received $11^{\text {th }}$ February 2020 Accepted $27^{\text {th }}$ February 2020

www.ijpefs.com a Department of Sport Games, Faculty of Physical Education and Sport, Charles University
Czech Republic.

*Corresponding Author Email: carboch@ftvs.cuni.cz

Abstract: Male and female players may have different game characteristics and performance. The first two shots of a rally in badminton have tactical importance. The aim of this study is to identify players' actions and behaviors and to assess differences in serve and return between the genders on the international level. We observed 15 male and 15 female matches from top international badminton tournaments. A notational analysis was used while observing the serve type, return type and the point winner. Male players hit the backhand short serve in $91 \%$ of points and female players started the point mostly with the forehand long serve (58\%). Both genders won $50 \%$ of the serving points. The distribution of return type is quite equal among the drop, lob, clear, smash and net shots in female matches. While returning a short serve, the lob was 4-5 \% less efficient than a net shot in both genders. Women can try to use backhand short serve more often as we found the highest efficiency of all the serve types.

Key Words: Notational Analysis, Tactics, Game Performance, Strategy

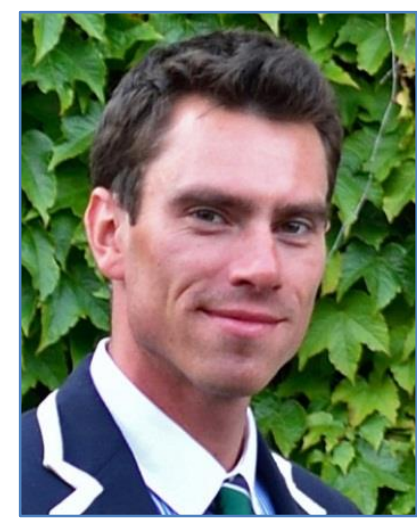

Dr. Jan Carboch, Ph.D. is a lecturer and sport scientist at Department of Sport Games, Faculty of Physical Education and Sport, Charles University. He graduated and finished his PhD. at the same University. His dissertation thesis was focused on visual perception and anticipation in tennis. His research interest is game performance and analyses, anticipation and visual perception in sport games and qualitative analyses of human movement. He is also involved in professional tennis as a tennis official.

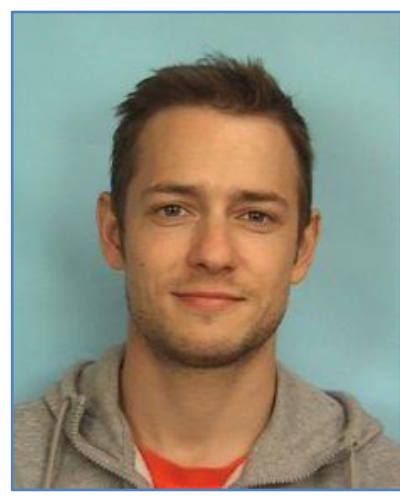

Mgr. Petr Smocek is a recent graduate of the Faculty of Physical Education and Sport, Charles University. His thesis was focused on tactical skills and strategy of badminton players. He has obtained a coaching license and is a 


\section{Jan Carboch and Petr Smocek /2020}

\section{Introduction}

Badminton is a fast and dynamic sport that involves quick reactions, fast movements and highspeed shots. Previously it was reported, that the rally in badminton has on average 5-9 shots [1-4]. The first two shots of a rally in badminton have tactical importance. The player can serve different types of serves and hit various types of return shots that impact the outcome of the rally [5, 6]. The most common serve in male competitions is the short serve [7]. The short serve should fly as low as possible over the net towards the service line to avoid the receiver's high impact point [8]. The long serve has a high ball trajectory towards the baseline (long service line) forcing the opponent to push back and hitting his return shot from the back of the court. The long serve is usually indicated by a server's backswing unless it is a flick serve (the server indicates to serve a short serve, but he hits a long serve with a minimum backswing and a lower trajectory to surprise the opponent). The serves can be played either by a forehand or backhand. The high serve is usually more used in female matches. Differences in game characteristics have been found between the elite male and female matches [1]. The return shot can be either offensive or defensive, depending on the serve quality. It depends if the receiver can intercept the short serve above the net, or if he/she can smash the high serve. Other basic shots are drop, lob, drive, clear or net shot.

Notational analyses of the matches can provide important information about the game performance or game characteristic, which can be useful for a scientist and coaches [1,9, 10]. It has been proposed the male and female players have different game characteristics, strategy and tactics $[4,11]$. The aim of this study is to identify players' actions and behaviors and to assess differences in serve and return between genders on the international level.

\section{Method}

\subsection{Materials and Procedures}

We observed 15 male and 15 female matches from top international badminton tournaments
(World Championship 2017, All England Open 2017). The male players were aged $25,6 \pm 4,7$ years and had a mean world ranking of $43,3 \pm 46,8$. The female players had a mean age of $22,4 \pm 3,9$ years and the world ranking $7,8 \pm 19,6$. This study was approved by the Ethics Committee at the Faculty of Physical Education and Sport, Charles University.

A notational analysis was used while observing matches. The matches were available on the internet (youtube.com). The quality of the streamed matches was considered satisfactory for the subsequent analysis. I case of an unclear situation, we had the option to review the action. The analysis was done by one independent evaluator, who was an expert badminton player and coach. In total, we analyzed 1241 male and 1251 female rallies.

\subsection{Data Analysis}

We analyzed the first two shots of the point, i.e. the serve and return shot. We observed following variables (1) serve type, i.e. short, flick or long serve; (2) serve execution i.e. forehand or backhand serve; (3) return shot type, i.e. drop, smash, lob, drive, clear or net shot; (4) point winner (to assess the efficiency). Data were analyzed using frequency analysis.

\section{Results and Discussion}

The servers, both male and female players, won $50 \%$ of their serving points. Details provide table 1. Female players had lower efficiency when they served from the left side. In male matches, there was no difference between the efficiency of serving from the right or the left side.

Male players used only 3 types of serves compared to 5 types of serves in female matches (details in table 2). Similar to [4, 12], we found that in most cases men preferred to serve a backhand short serve (in $91 \%$ of rallies), but conversely, women mostly served forehand long serve (in $58 \%$ of rallies). In our study, the female players used the short serve in $38 \%$ of cases (forehand and backhand short serve with even distribution). Valldecabres et al. [4] reported that also women 


\section{Jan Carboch and Petr Smocek /2020}

used the short serve most, which can be attributed to specific analyses of one match (World Championship final) only. Interestingly, the women reached the highest efficiency when they served the backhand short serve. Various strategies are taking part in women's matches and the long serve tactics and forehand serves make the game characteristics different between the genders. The return shot is based on the serve type delivery. Like in other sports [13], the receiver needs to react as soon as possible.
Male players need to return the short serve and therefore the lobs and net shots are the most common (Table 3). The male players used the lob return more often compared to female players. That agrees with Ming et al. [14], who say that men use more lob shots in the match. However, in our study we explain this result due to more short serves in male matches and therefore players hit more shots from the front part of the court close to the net. Male players had a poor efficiency to score a point when they used a drop shot return.

Table 1 Comparison of serving side and efficiency between the genders

\begin{tabular}{lrrrr}
\hline & \multicolumn{2}{c}{ Men } & \multicolumn{2}{c}{ Women } \\
\hline $\begin{array}{l}\text { Serving } \\
\text { side }\end{array}$ & Frequency & Efficiency & Frequency & Efficiency \\
\hline Right & 629 & $51,0 \%$ & 635 & $52,0 \%$ \\
Left & 612 & $50,8 \%$ & 616 & $48,7 \%$ \\
\hline Total & 1241 & $50,9 \%$ & 1251 & $50,4 \%$ \\
\hline
\end{tabular}

Table 2 Comparison of serve type and efficiency between the genders

\begin{tabular}{|c|c|c|c|c|}
\hline & & Men & & Women \\
\hline Serve type & Frequency & Efficiency & Frequency & Efficiency \\
\hline Backhand short & 1131 & $51,2 \%$ & 231 & $52,8 \%$ \\
\hline Forehand short & 27 & $40,7 \%$ & 249 & $49,4 \%$ \\
\hline Backhand flick & 83 & $50,6 \%$ & 12 & $50,0 \%$ \\
\hline Forehand flick & 0 & - & 28 & $46,4 \%$ \\
\hline Forehand long & 0 & - & 731 & $50,1 \%$ \\
\hline Total & 1241 & $50,9 \%$ & 1251 & $50,4 \%$ \\
\hline
\end{tabular}

Table 3 Comparison of return type and efficiency between the genders

\begin{tabular}{lrrrr}
\hline & \multicolumn{2}{c}{ Men } & \multicolumn{2}{c}{ Women } \\
\hline $\begin{array}{l}\text { Return } \\
\text { type }\end{array}$ & Frequency & Efficiency & Frequency & Efficiency \\
\hline Drop & 32 & $37,5 \%$ & 229 & $52,8 \%$ \\
Clear & 14 & $50,0 \%$ & 234 & $49,4 \%$ \\
Net shot & 578 & $51,2 \%$ & 201 & $50,0 \%$ \\
Lob & 505 & $46,3 \%$ & 241 & $46,4 \%$ \\
Smash & 35 & $62,9 \%$ & 268 & $50,1 \%$ \\
Drive & 38 & $63,2 \%$ & 22 & $50,4 \%$ \\
\hline Total & 1202 & $49,5 \%$ & 1197 & $50,9 \%$ \\
\hline
\end{tabular}




\section{Jan Carboch and Petr Smocek /2020}

Allowing the server a net play may offer the receiver more chances to win the point. However, the frequency of drop return is very low due to the short serves in male matches. On the other hand, in female matches, the drop shot return was very efficient. The distribution of return type is quite equal among the drop, lob, clear, smash and net shots in female matches. This is based on the server's strategy and on the chosen serve type. From this point of view, the serving and receiving the action is more variable in female matches.

\section{Conclusion}

We found differences in players' behavior and game characteristics between the genders. Women use mostly the forehand long serve compared to men, who prefer the backhand short serve and do not use the forehand long serve at all. The authors are aware that individual strategy affects particular matches, match parts and match development. We have a few suggestions for consideration based on our results. Women can try to use backhand short serve more often as we found the highest efficiency of all the serve types. We suggest not using the lob return shot very often in both genders due to lower efficiency.

\section{References}

[1] J. Abian-Vicen, A. Castanedo, P. Abian, J. Sampedro, Temporal and notational comparison of badminton matches between men's singles and women's singles, International Journal of Performance Analysis in Sport, 13 (2013) 310-320.

[2] D. Cabello, J.J. González-Badillo, Analysis of the characteristics of competitive badminton, [11] British journal of sports medicine, 37 (2003) 62-66.

[3] O. Faude, T. Meyer, F. Rosenberger, M. Fries, G. Huber, W. Kindermann, Physiological characteristics of badminton match play, European journal of applied physiology, 100 (2007) 479-485.
[4] R. Valldecabres, A.M. De Benito, C.A. Casal, C. Pablos, 2015 Badminton World Championship: Singles final men's vs women's behaviours, Journal of Human Sport and Exercise, 12 (2017) S775-S788.

[5] S. Li, Analysis on skills and tactics of serve and return of service of Chinese badminton men doubles and foreign ones, Journal of Wuhan Institute of Physical Education, 39 (2005) 84-87.

[6] Z. Liu, M. Zheng, An analysis of service skill of world badminton men's doubles, Journal of Hubei Sports Science, 28 (2009) 112-118.

[7] W. Gawin, C. Beyer, H. Hasse, D. Büsch, How to attack the service: an empirical contribution to rally opening in world-class badminton doubles, International Journal of Performance Analysis in Sport, 13 (2013) 860-871.

[8] I. Hussain, S. Ahmed, A. Mohammad, A. Khan, M. Arshad Bari, Videographical Analysis of Short Service in Badminton, Journal of Education and Practice, 2 (2011) 1-5.

[9] Y. Hong, Y. M. Tong, "The playing pattern of the world's top single badminton players in competition - a notation analysis", Journal of Human Movement Studies, vol. 38, pp.185200, 2000 .

[10] G. Laffaye, M. Phomsoupha, F. Dor, Changes in the Game Characteristics of a Badminton Match: A Longitudinal Study through the Olympic Game Finals Analysis in Men's Singles, Journal of sports science \& medicine, 14 (2015) 584- 590.

H. L. Chen, T. C. Chen, Temporal structure comparison of the new and conventional scoring systems for men's badminton singles in Taiwan, Journal of Exercise Science and Fitness, 6 (2008) 34-43.

E. Oswald, A computer - aided comparison of the playing pattern of the world's top male players and Austrian top male players in single badminton, University of Viena, Austria, (2006). 
Jan Carboch and Petr Smocek /2020

[13] S. Balkó, J. Heidler, M. Jelínek, Relationship between the armed arm's motor response and muscle activation time during the lunge in fencers of varied ability, Journal of Human Sport and Exercise, 13 (2018) 50-59.

[14] C.L. Ming, C.C. Keong, A.K. Ghosh, Time motion and notational analysis of 21 point and 15 point badminton match play, International Journal of Sports Science and Engineering, 2 (2008) 216-222.

\section{Acknowledgement}

This study was written within the Programme of the institutional support for science at Charles University, Progress, No.Q41 Biological aspects of the investigation of human movement

\section{Conflict of interest}

None of the authors have any conflicts of interest to declare.

\section{Informed consent}

All participants gave written informed consent to participate in this study.

\section{About The License}

\section{(1)(1)}

Attribution 4.0 International (CC BY 4.0)
The text of this article is licensed under a Creative Commons Attribution 4.0 International License 